\title{
Storytelling: the soul of science communication
}

\section{Marina Joubert, Lloyd Davis and Jenni Metcalfe}

\begin{abstract}
There is a renewed interest amongst science communication practitioners and scholars to explore the potential of storytelling in public communication of science, including to understand how science storytelling functions (or could fail) in different contexts. Drawing from storytelling as the core theme of the 2018 conference of the Public Communication of Science and Technology (PCST) Network, we present a selection of papers, essays and practice insights that offer diverse perspectives. Some contributions focus on the cultural and structural qualities of science stories and its key success factors, while others explore new formats, platforms and collaborators in science storytelling activities.
\end{abstract}

\section{Keywords}

DOI
Informal learning; Public engagement with science and technology; Science and technology, art and literature

https://doi.org/10.22323/2.18050501

Submitted: 27th September 2019

Accepted: 27th September 2019

Published: 14th October 2019

In a world where we increasingly look towards science and technology to find answers that will help us secure a fair and sustainable future, it is imperative that people become empowered to make informed decisions about issues rooted in science. To achieve this, science communicators must make science-related information engaging and relevant. In short, it is about making people care. That is why we need to go beyond presenting facts and evidence, towards creating emotional connections between scientists and publics.

Thinking of stories as facts wrapped in emotions [Olson, 2009] may be the answer. That is why science communicators looking for ways to help people make sense of science and care about science-related issues, have renewed their attention on the potential of storytelling as a tool when communicating about science. We now have ample evidence that storytelling can be a powerful way to nurture engagement with science [Dahlstrom, 2014] and that stories help people to understand, process and recall science-related information [ElShafie, 2018].

All animals (and many plants) communicate in one way or another, but only humans tell stories. Storytelling is arguably the defining characteristic of humans that sets us apart from the animal kingdom and our hominin ancestors. Stories 
have been used to pass on wisdom, knowledge, and culture and to strengthen social bonds since the earliest times of humankind's existence. Our lineage advanced because we could communicate in abstract terms about the world in which we lived. Ancient societies told stories around campfires and painted murals about their hunting expeditions on the walls of caves. This enabled our ancestors to process information and make meaning of their shared experiences [Coen, 2019].

Stories typically have a beginning, a middle and an end, a structure that is also known as a 'narrative arc'. The unexpected twists and turns that characterize a good storyline, build tension and keep the attention of readers, listeners and viewers. Another key characteristic of a story is that, at the end, the plot is resolved and something changes [Storr, 2019]. It is through understanding the reasons for this change that stories impart meaning and can change the way people see the world. Once communicators understand and tap into this aspect of storytelling, stories can become versatile tools to help people make sense of the world around them, including issues and developments rooted in science. Moreover, when people identify with the characters in a story, and when the views and values of the story characters resonate with their own, stories help them to make informed decisions about these issues in their own lives. Successful stories can compel people to act or change their behaviour or may ignite interest to discover more about a specific topic.

However, the ubiquity of online digital technologies is changing the way people encounter and consume stories and, importantly, the tools available to science communicators to tell stories [Holliman, 2011]. Therefore, it is crucial that we understand the role of storytelling and how to employ it as a tool in a digital communication environment. With this in mind, storytelling was the central theme of the 2018 Public Communication of Science and Technology (PCST) Conference in New Zealand.

The six papers in this special issue are by authors who presented at PCST 2018. However, this issue does not constitute a full set of proceedings from the conference. Rather, it is a compilation of ideas and perspectives about storytelling that emanated from the conference.

In the first paper, Sarah Davies, Megan Halpern, Maja Horst, David Kirby and Bruce Lewenstein establish that science stories are an integral part of culture. It is through storytelling about science, they argue, that science communication both shapes culture and formulates meanings that determine our identities. Taking a cultural approach, the authors offer a nuanced perspective on the diverse nature of science communication that may, as they suggest, help us to move beyond the 'deficit vs dialogue' debate in our field.

However, not all stories are created equal. Craig Cormick [2019] delves into the neural and psychological evidence to explore how and why stories affect us and what make a good story, but also how a good story is told. Success, he argues, depends on understanding the tools of storytelling and making sure that our stories resonate with people's experiences and values.

Wiebke Finkler and Bienvenido León [2019] provide a framework for telling better visual stories when communicating science through what is fast becoming the main way that the public, especially its younger members, consume media: online 
on-demand short-format videos. They demonstrate that using their SUCCESS formula when communicating in an online world - where there is a staggering abundance of alternative material competing for an audience's eyes and ears - can not only communicate science effectively, it can also change people's attitudes.

Fredrik Brounéus, Maria Lindholm and Gustav Bohlin used a focus-group study in Sweden to show that public attitudes to science are shaped by different narratives [2019]. Four influential themes emerged from the study that could either enhance or detract from storytelling's effectiveness depending upon how they were represented: the persons conducting the science, the process by which the scientific research was undertaken, the results of the research, and how the results were communicated.

This interplay between storytelling and culture, perceptions and science, is at the core of the paper by Kaitlyn Martin, Lloyd Davis, and Susan Sandretto [2019]. They argue that in schools we should be concentrating on training storytellers about science rather than story-listeners. It is the very technology that is changing the way we consume stories, that can enable such a pedagogical shift: by having students make films about science using mobile smartphones and tablets, which can even be distributed online.

Finally, Michelle Riedlinger, Jenni Metcalfe, Ayelet Baram-Tsabari, Marta Entradas, Marina Joubert and Luisa Massarani [2019] provide a practice insight in which they contend that science communication, as a discipline, can benefit from combining practice with theory. Any science communication conference, such as PCST 2018, reveals that science communication exists as two largely discrete parts: on one hand there are the researchers and scholars of science communication who grapple with theories and measure the processes and effectiveness of science communication; on the other hand there are the practitioners, who do the actual communicating with publics about science. From a series of case studies, the message from these authors becomes clear: when scholars of science communication collaborate with practitioners of science communication involved in storytelling, the effectiveness of both groups is enhanced.

As this collection of six papers attest, storytelling is the common thread that binds much of our efforts in science communication, be we scholars or practitioners or some combination of both. At future conferences, it is our sincere hope that any divide will be much less apparent than the things that binds us. Instead of there being "something of a gulf between the practical science communication community and the body of researchers," as Steve Miller [2008] once observed, we hope there will be recognition that we have a common soul: storytelling.

\section{References}

Brounéus, F., Lindholm, M. and Bohlin, G. (2019). 'Telling it straight — a focus group study on narratives affecting public confidence in science'. JCOM 18 (05), A03. https://doi.org/10.22323/2.18050203.

Coen, E. (2019). 'The storytelling arms race: origin of human intelligence and the scientific mind'. Heredity 123 (1), pp. 67-78.

https://doi.org/10.1038/s41437-019-0214-2.

Cormick, C. (2019). 'Let me tell you a story'. JCOM 18 (05), Y01. https://doi.org/10.22323/2.18050401. 
Dahlstrom, M. F. (2014). 'Using narratives and storytelling to communicate science with nonexpert audiences'. Proceedings of the National Academy of Sciences 111 (Supplement 4), pp. 13614-13620. https://doi.org/10.1073/pnas.1320645111.

Davies, S. R., Halpern, M., Horst, M., A. Kirby, D. A. and Bruce Lewenstein (2019). 'Science stories as culture: experience, identity, narrative and emotion in public communication of science'. JCOM 18 (05), A01. https://doi.org/10.22323/2.18050201.

ElShafie, S. J. (2018). 'Making science meaningful for broad audiences through stories'. Integrative and Comparative Biology 58 (6), pp. 1213-1223. https://doi.org/10.1093/icb/icy103.

Finkler, W. and León, B. (2019). 'The power of storytelling and video: a visual rhetoric for science communication'. JCOM 18 (05), A02. https://doi.org/10.22323/2.18050202.

Holliman, R. (2011). 'Telling science stories in an evolving digital media ecosystem: from communication to conversation and confrontation'. JCOM 10 (04), C04. https://doi.org/10.22323/2.10040304.

Martin, K. M., Davis, L. S. and Sandretto, S. (2019). 'Students as storytellers: mobile-filmmaking to improve student engagement in school science'. JCOM 18 (05), A04. https://doi.org/10.22323/2.18050204.

Miller, S. (2008). 'So Where's the Theory? on the Relationship between Science Communication Practice and Research'. In: Communicating Science in Social Contexts. New models, new practices. Ed. by D. Cheng and M. Claessens. Brussels, Belgium: Springer, pp. 275-287. https://doi.org/10.1007/978-1-4020-8598-7_16.

Olson, R. (2009). Don't be such a scientist: talking substance in an age of style. Washington, DC, U.S.A.: Island Press.

Riedlinger, M., Metcalfe, J., Baram-Tsabari, A., Entradas, M., Joubert, M. and Massarani, L. (2019). 'Telling stories to build collaboration between science communication scholars and practitioners'. JCOM 18 (05), N01. https://doi.org/10.22323/2.18050801.

Storr, W. (2019). The science of storytelling. London, U.K.: William Collins.

Marina Joubert is a senior science communication researcher at the Centre for Research on Evaluation, Science and Technology (CREST) at Stellenbosch University, South Africa. Her research interests focus on scientists' role in public communication of science, online interfaces between science and society and the changing policy environment for public communication of science in Africa. She is also interested in the communication of contested topics in science, in particular the vaccine debate. In addition to her teaching and research duties, she presents an annual online course for science communicators across Africa and provides hands-on science communication workshops for researchers.

E-mail: marinajoubert@sun.ac.za. 
Lloyd S. Davis is an internationally recognised scientist, as well as an award-winning author and filmmaker. Currently the inaugural Stuart Professor of Science Communication at the University of Otago, he has authored 150 refereed publications on topics ranging from behavioural ecology to science communication and science diplomacy. E-mail: 1loyd.davis@otago.ac.nz.

Jenni Metcalfe is Founder of Econnect Communication, established in 1995 to help scientists communicate their research. As a science communicator for 30 years, she has worked as a journalist, practitioner, university lecturer and researcher. She believes every person has a right to engage with science, so they can make more informed decisions about issues that affect their lives. Jenni is a member of the Scientific Committee of the Public Communication of Science and Technology (PCST) Global Network. E-mail: jenni@econnect.com.au.

How to cite

Joubert, M. Davis L. and Metcalfe, J. (2019). 'Storytelling: the soul of science communication'. JCOM 18 (05), E. https:/ / doi.org/10.22323/2.18050501. 